\title{
The effects of pediatric primary prevention programs on screen-time and reading habits of children in Jordan
}

\author{
Mustafa S. Yousuf ${ }^{*}$ (D), Heather Lea Harvey ${ }^{1}$, Sanjai K. Parahoo², Basil Shawkat Ziadeh', Muna Kilani ${ }^{3}$ and \\ Eman Al-Kamil ${ }^{1}$
}

*Correspondence: msysalman@yahoo.com 1 Department of Basic Medical Sciences, Faculty of Medicine, The Hashemite University, Zarqa, Jordan Full list of author information is available at the end of the article

\begin{abstract}
The proliferation of electronic content and limited exposure of children to books in Jordan has made both parents and health-care providers more concerned about healthy child development. This research aimed to determine if pediatric primary prevention programs were helpful in reducing screen-time and improving reading habits of children in Jordan, and if there was a correlation between these two factors. Parents attended classes on various topics, one of which dealt with screen-time and reading. Six months later, they were surveyed on these topics. The test group (took the relevant class) and control group (did not take the class) included 30 families each. The mean screen-time was above the recommended guideline of $2 \mathrm{~h} /$ day in both groups. Only $37 \%$ of the families in the test group, and $17 \%$ in the control group followed the guideline. A significant difference in screen-time between the groups was found only during weekends. When asked about the ideal screen-time, parents from the test group reported screen-times that were significantly closer to the recommendations, showing an increase in knowledge, but not a significant change in behavior. Parents, also, believed that children's exposure to books should be at the much later age of 3-4 years, with actual exposure being $<1 \mathrm{~h} /$ day. Moreover, no correlation was found between screen-time and reading time. These findings suggest that short, evidencebased classes helped raise awareness, but were not sufficient for parents to fully adopt the guidelines. Programs that promote behavior modification should be explored to reinforce knowledge gained from educational classes.
\end{abstract}

Keywords: Jordan, Pediatric primary prevention, Screen-time, Reading, Parenting, Mobile devices

\section{Introduction}

Since the arrival of television sets in homes, each generation has faced the dilemma of how much time children should be allowed to watch them. As technology evolved, this problem has expanded to other electronic screen devices. Today, screen-time includes the time a child spends watching television, playing video games, browsing the internet, or using any mobile or tablet device. Such media can be used to deliver educational content or to promote positive behavior like good manners, sharing, forgiveness, and others

(c) The Author(s), 2021. Open Access This article is licensed under a Creative Commons Attribution 4.0 International License, which permits use, sharing, adaptation, distribution and reproduction in any medium or format, as long as you give appropriate credit to the original author(s) and the source, provide a link to the Creative Commons licence, and indicate if changes were made. The images or other third party material in this article are included in the article's Creative Commons licence, unless indicated otherwise in a credit line to the material. If material is not included in the article's Creative Commons licence and your intended use is not permitted by statutory regulation or exceeds the permitted use, you will need to obtain permission directly from the copyright holder. To view a copy of this licence, visit http:// creativecommons.org/licenses/by/4.0/. 
which are beneficial to a child. The inappropriate and excessive use of such devices, however, has been related to harmful consequences (Canadian Paediatrics Society, 2017; Stiglic \& Viner, 2019).

The American Academy of Pediatrics Council on Communication and Media (2013) has recommended $2 \mathrm{~h}$ /day as the maximum screen-time allowed for children and teenagers, and for children under two, no screen-time exposure was recommended. Children using screen devices for more than this recommended time have been found to be at a higher risk for developing several serious conditions. The association of excessive screen-time with obesity has been reported in Jordan (Al-Dalaeen and Al-Domi, 2017), other countries in the region like Qatar (Bener, 2011) and Saudi Arabia (Al-Ghamdi, 2013), and globally in China (Zhu et al., 2018), Sweden (Garmy et al., 2018), and the US (Kenney \& Gortmaker, 2017), among others. Too much screen-time was related to abnormal sleeping patterns (Nathanson \& Beyens, 2018; Twenge et al., 2017), increased risk of developing asthma and other allergies (Mitchell et al., 2013), and poor performance on developmental screening tests (Madigan et al., 2019).

Not only have studies indicated physiological associations, but also a correlation between a high level of screen-time and psychosocial problems in children (Khan et al., 2018; Parent et al., 2016), the subsequent development of attention problems (Swing et al., 2010), and poor school performance (Faught et al., 2017; Sharif \& Sargent, 2006). With regard to acquiring knowledge, children below the age of three who were learning from screen devices were found to have difficulty transferring what they have learned from the 2D context (the screen) to 3D practice in real life (Barr, 2010).

The effect of screen-time on children's health, well-being, and personal development, therefore, cannot be overlooked. In Jordan, $98 \%$ of households own a mobile phone (Department of Statistics/Jordan and ICF, 2019). In the US, 95\% of families possess a smartphone (Wolf et al., 2018). Various methods have been tried to limit children's screen-time. Schmidt et al. (2012) reported the success of feedback reward systems in reducing screen-time. In this method, children were awarded screen-time according to their physical activity. This metanalysis also reported that the use of television-monitoring devices also effectively lowered screen-time by electronically limiting the time allowed for children to watch television. Other programs encouraged physical activity, like dancing (Robinson et al., 2010) and playing video games that encouraged physical activity (Lanningham-Foster et al., 2006). Sherwood et al. (2019) recruited families from the pediatrics primary care clinics. These were given a brief primary care counseling about the prevention of obesity in the clinic followed by several, at home, phoned-based training. This had no significant effect on screen-time. A mixed approach was used by others (Habib-Mourad et al., 2014; Paw et al., 2008) to promote healthy behaviors. This included classes presented to children in their schools, meetings with families, giving handouts to families, and providing healthy food for school cafeteria. Despite this multicomponent approach, no effect on screen-time was recorded. Harrison et al. (2006) conducted educational classes in schools with some success. Buscemi et al. (2019) used educational programs that aimed at preventing obesity including the relevance of reducing screen-time with no effect. In Jordan, no intervention programs were previously employed to reduce children's screen-time. Two metanalyses (Schmidt et al., 2012; Wu et al., 2016), found that intervention programs were effective in reducing screen-time. 
This depended on the duration of the program and the method employed. Schmidt et al. (2012) found that educational programs delivered at the clinic were highly effective. Therefore, and because it was the most logistically feasible, this method was chosen for our research.

Reading is one activity that can be used to reduce screen-time (Khan et al., 2017), and a reading plan suitable for a particular culture can be easily designed. Reading to children or encouraging them to read on their own is one of the most fruitful behaviors, and has been shown to have a positive effect on their cognitive abilities (Murray \& Egan, 2014). Moreover, promoting reading to preschoolers was shown to enhance their vocabulary (Hargrave \& Sénéchal, 2000), and school children who were better at reading during their initial school years, had a higher chance of graduating high-school and even enrolling in college (Lesnick et al., 2010). Furthermore, finding the right way to motivate children to read by themselves enhances their ability to comprehend what they read (Wigfield et al., 2016).

On the other hand, watching television has been shown to reduce the time children read books (Beentjes \& van der Voort, 1989; Koolstra \& van der Voort, 1996). This could be due to the time taken up by television viewing or it may be due to the content of the programs. Interactive media (like those found on today's mobile devices) may adversely affect the concentration of children while reading (Wang et al., 2019). The use of e-books instead of paper books was found to be associated with less verbalization while reading by both parents and children (Munzer et al., 2019) and less warm interactions between parent and child (Yuill \& Martin, 2016). So, encouraging parents to read to their children at a young age, especially printed books, and finding the proper motivation for older children to read by themselves can have great benefits to those children, including potentially providing a healthy substitute for screen-time.

Therefore, this research aimed to assess whether pediatric primary educational programs provided to parents were effective in reducing the screen-time of children in Jordan and enhancing their reading habits. In addition, the study aimed to assess if there was a correlation between screen-time and reading time.

\section{Methods}

During the months of October and November 2017, families seeking services from the pediatric out-patient clinic in a large public hospital in Amman, Jordan, were asked if they wanted to participate in pediatric primary prevention classes during their idle waiting time. These classes were prepared by a pediatrician member of this research team using evidence-based references. A group of qualified pediatricians and community medicine specialist reviewed these lectures and gave their feedback. The authors studied the feedback and modified the lectures accordingly until a final version was approved. A member of the team who was fluent in English and Arabic translated the material into Arabic (the native language of the participants). When the translated version was approved by the entire team, the lectures were made into Microsoft PowerPoint presentations to be used in the actual educational classes. The classes were made to take about $20 \mathrm{~min}$. This was done because the participants were waiting to be called for their doctor's appointment and making the classes longer might have deterred them from participating. 
The authors who are fluent in Arabic all participated in the presentation of the classes to the participants. To help with this task, fourth and fifth year medical students were enrolled. These were divided into teams and given the materials to study. The authors gave several training sessions to these teams on how to present a lecture and how to be prepared to answer questions by the attendees. The training was held in lecture halls either in the university campus or in the hospital where the research was done. The student teams that were approved by the authors were allowed to give the educational classes.

There were three different evidence-based classes: (1) child nutrition, (2) child injury prevention, and (3) child developmental milestones. The families could choose to participate in any, all, or none of the classes offered. The classes were held in a lecture hall close to the out-patient clinic and on specified times according to a predetermined time-table. When the time of the class came, the families participating in that class were guided by medical students to the lecture hall. About 15-20 people were allowed in each class to make it easier for the participants to listen to the lecture and ask questions. In the child development class, the major developmental milestones were explained according to the various ages of children (less than 1 year, $1-3$ years, $3-5$ years, and 5-10 years). Also, the parents were given some simple points that may indicate abnormal development in their children. In addition, the main effects of excessive screen-time on children were briefly explained in this class and the recommended guidelines were given and alternative activities suggested. Concerning reading, the main benefits of reading to children starting from a very young age were emphasized. Pamphlets (in Arabic) were given to the families after the class. These contained a summary of the main points discussed in the class.

Six months after the completion of the classes (May/June 2018), participating families were surveyed, through telephone, specifically about the subjects of screen-time and reading habits to assess their adoption of the recommendations given to them during the classes. A short survey questionnaire was developed and discussed by three academics in the field to establish face validity. Back translation (Brislin, 1970) was used to develop an Arabic version of the questionnaire. For the purposes of this study, the families were divided into two groups: (1) the test group-included the families that participated in the developmental milestones class that included evidence-based materials on screentime and reading habits for children, and (2) the control group-included the families that did not participate in the developmental milestones class, but that participated in one of the other prevention classes, and therefore were not exposed to the evidencebased materials on screen-time and reading.

Both groups were surveyed on the following questions:

Regarding screen-time:

1) How many hours per day does your child use screen devices (television, mobile, tablet, or computer) during weekdays?

2) How many hours per day does your child use screen devices (television, mobile, tablet, or computer) during weekends?

3) How many hours per day do you think it is appropriate for your child to use screen devices? 
Regarding reading habits:

1) In your opinion, what is the appropriate age to start reading to your child?

2) How much time do you spend reading to your child or your child spends reading in a day? (asking specifically about non-school-related reading).

The average daily screen-time was determined using a weighted average of weekdays (5 days) and weekend ( 2 days) screen-times. For each family surveyed, the following demographics were recorded: the age of the parent, the number of children in the family, and the age of the children.

The data obtained were tabulated and analyzed using Microsoft Excel and IBM SPSS version 25 software and the two groups were statistically compared using t-tests. To find if there was a correlation between screen-time and reading time in each of the groups, a Pearson product-moment correlation was used.

\section{Results}

\section{Groups}

The test group included a total of 56 families. The control group included a total of 58 families. From each group, only 30 families responded to our calls during the follow-up survey. The rest were unable to be reached, either because they did not provide their contact number when they enrolled in the prevention classes, or they did not answer their phones when called.

\section{Confounding factors}

Compliance with guidelines presented in the primary prevention program could have been related to several potential factors, besides those being measured. Three demographic factors were considered in this research: age of parent, number of children in the family, and the age of the children. To assess the differences, if any, between the two groups an independent samples $t$-test was conducted. The results showed that the two groups did not display any significant differences in the mean values of any of these factors, and the two groups could, thus, be considered homogeneous with regard to these three factors (see Table 1).

Table 1 Differences between the two groups with regard to the confounding factors

\begin{tabular}{|c|c|c|c|c|c|c|c|}
\hline Factor & Group & Number & Mean & $\begin{array}{l}\text { Standard } \\
\text { deviation }\end{array}$ & $95 \% \mathrm{Cl}$ of difference ${ }^{\mathrm{a}}$ & $\begin{array}{l}t \text {-value } \\
(\mathrm{df})^{\mathrm{b}}\end{array}$ & $p$-value \\
\hline \multirow[t]{2}{*}{ Age of parent } & Test & 30 & 36.73 & 8.00 & {$[-5.20,3.67]$} & $-0.35(56)$ & 0.730 \\
\hline & Control & 28 & 37.50 & 8.85 & & & \\
\hline \multirow[t]{2}{*}{ Number of children } & Test & 30 & 4.00 & 1.82 & {$[-0.96,0.89]$} & $-0.07(58)$ & 0.943 \\
\hline & Control & 30 & 4.03 & 1.75 & & & \\
\hline \multirow[t]{2}{*}{ Age of children ${ }^{c}$} & Test & 115 & 11.67 & 6.31 & {$[-1.12,2.13]$} & $0.61(234)$ & 0.541 \\
\hline & Control & 121 & 11.17 & 6.34 & & & \\
\hline
\end{tabular}

${ }^{a}$ Difference was calculated as Test-Control. Cl, confidence interval

${ }^{b} \mathrm{df}$, degrees of freedom

${ }^{\mathrm{C}}$ All the children in all the families in each group were considered in these calculations 


\section{Screen-time}

The three screen-time questions were individually examined using an independent samples t-test. The average daily screen-time was calculated as a weighted average and then analyzed. The time children in the families from the test group spent on screen devices during weekends $(M=3.70 \mathrm{~h})$ was significantly different from that of children from the control group $(M=5.15 \mathrm{~h})$. No difference was, however, seen when looking at the weekdays' screen-time, or when considering the weighted average for the whole week (see Table 2).

Looking at the mean screen-time during weekdays, weekends, and the average screentime, they were higher than the recommended $2 \mathrm{~h} /$ day, in both groups. Based on the average screen-time, the percentage of children who were, actually, limited to a maximum screen-time of $2 \mathrm{~h}$ /day was only $37 \%$ for those whose parents had participated in the developmental milestones class (test group), but this was still more than the $17 \%$ for the control group.

When asked about the ideal screen-time for children, the test group reported an average of $1.60 \mathrm{~h}(S D=0.87, n=30)$, while the control group reported an average of $1.88 \mathrm{~h}$ $(S D=1.68, n=28)$. When these means were compared to the recommended $2 \mathrm{~h} /$ day (using a one-sample t-test), an interesting finding emerged: the mean of the test group was significantly different from the recommended threshold, $t(29)=-2.53, p=0.017$, $95 \%$ CI $[-0.72,-0.08]$; whereas, the mean of the control group was not significantly different from the recommended $2 \mathrm{~h} /$ day, $t(27)=-0.39, p=0.697,95 \%$ CI $[-0.78$, 0.53]. This suggests that the parents in the test group were more aware of the need to limit the daily screen-time to below the recommended threshold.

\section{Reading habits}

For this aspect of the study, the families from the test and control groups were surveyed on the two reading habits questions and the responses were then analyzed using an independent samples t-test. The results showed that the families in the test group believed that they should start reading to their children at about 3 years of age compared to just over 4 years for the controls $(M=2.98, S D=1.79$; and $M=4.20, S D=2.24$, respectively). Children's reading time (the time parents read to their children and/ or the time children spent reading) was about $43 \mathrm{~min} /$ day for the children in the test group $(M=0.72 \mathrm{~h}, S D=0.82)$, compared to about $16 \mathrm{~min} /$ day for the control parents

Table 2 Differences between the two groups with regard to screen-time

\begin{tabular}{|c|c|c|c|c|c|c|c|}
\hline Question & Group & Number & Mean & $\begin{array}{l}\text { Standard } \\
\text { deviation }\end{array}$ & $95 \% \mathrm{Cl}$ of difference ${ }^{a}$ & $\begin{array}{l}t \text {-value } \\
(\mathrm{df})^{\mathrm{b}}\end{array}$ & $p$-value \\
\hline \multirow[t]{2}{*}{ Weekdays screen-time } & Test & 30 & 2.92 & 1.66 & {$[-1.61,0.41]$} & $-1.19(58)$ & 0.238 \\
\hline & Control & 30 & 3.52 & 2.20 & & & \\
\hline \multirow[t]{2}{*}{ Weekend screen-time } & Test & 30 & 3.70 & 1.69 & {$[-2.50,-0.40]$} & $-2.76(58)$ & 0.008 \\
\hline & Control & 30 & 5.15 & 2.32 & & & \\
\hline \multirow[t]{2}{*}{ Average screen-time ${ }^{c}$} & Test & 30 & 3.14 & 1.59 & {$[-1.79,0.11]$} & $-1.77(58)$ & 0.081 \\
\hline & Control & 30 & 3.98 & 2.06 & & & \\
\hline
\end{tabular}

a Difference was calculated as Test-Control. $\mathrm{Cl}$, confidence interval

${ }^{b} \mathrm{df}$, degrees of freedom

c Calculated as the weighted average 
$(M=0.27 \mathrm{~h}, S D=0.44)$. Analysis showed that the differences were statistically significant for both of these aspects of reading habits (see Table 3).

\section{Screen-time-reading time correlation}

To find if there was a relationship between screen-time and reading time, a Pearson product-moment correlation was run. For the test group $(n=30)$, no significant correlation was found between these two factors, $r(28)=0.11, p=0.562$. This test also yielded no correlation between screen-time and reading time for the control group $(n=30)$, $r(28)=-0.06, p=0.766$.

\section{Discussion}

For both the test and control groups, the majority of children used screen devices for more than the recommended $2 \mathrm{~h}$ a day $(63 \%$ of families in the test group with a mean screen-time of 3.14 , and $83 \%$ of families in the control group with a mean screen-time of 3.98). In a previous study in Jordan among teenagers aged 14-18 years, the percentage of those who used screen devices above the recommendation was $96 \%$ with a mean screen-time of about $7 \mathrm{~h}$ /day (Tayyem et al., 2014). A high screen-time of $6 \mathrm{~h} /$ day was also reported in school children aged 14-19 in Saudi Arabia (Al-Hazzaa et al., 2012), and $5 \mathrm{~h}$ /day for school children in Lebanon (Chacar \& Salameh, 2011). In the US, in 2008 , the percentage of children aged 4-11 who crossed the screen-time threshold was 65\% (Anderson et al., 2008), and, in 2013, it was 46\% for children aged 6-11 (Fakhouri et al., 2013). In Australia, it was $41 \%$ for preschool children (Hinkley et al., 2012), and, in China, 26\% of adolescents aged 11 to 16 years reported screen-time of more than $2 \mathrm{~h} /$ day (Cao et al., 2011).

Although the percentages differed from study to study and from country to country, they all failed to meet the expectations of the recommended guidelines. Despite being lower than the previous studies in Jordan, Saudi Arabia, and Lebanon, the findings obtained in this study for children's screen-time in Jordan were very high. Possible reasons include sedentary lifestyles, excessive use of computers for homework, and the absence of other perceived alternatives for spending free time such as reading (as this study results indicated children spent less than $1 \mathrm{~h}$ a day reading). Another important factor is that children may consider mobile devices as a means to be in semi-constant contact with their friends through messages and social networks, and, at the same time, be independent from their parents (Ling \& Haddon, 2008).

Table 3 Differences between the two groups with regard to reading habits

\begin{tabular}{|c|c|c|c|c|c|c|c|}
\hline Question & Group & Number & Mean & $\begin{array}{l}\text { Standard } \\
\text { deviation }\end{array}$ & $95 \% \mathrm{Cl}$ of difference ${ }^{\mathrm{a}}$ & $\begin{array}{l}t \text {-value } \\
\text { (df) }^{b}\end{array}$ & $p$-value \\
\hline \multirow{2}{*}{$\begin{array}{l}\text { What is the appropriate } \\
\text { age to start reading to } \\
\text { your child? }\end{array}$} & Test & 30 & 2.98 & 1.79 & \multirow[t]{2}{*}[-2.28,-0.15]{} & \multirow[t]{2}{*}{$-2.29(56)$} & \multirow[t]{2}{*}{0.026} \\
\hline & Control & 28 & 4.20 & 2.24 & & & \\
\hline \multirow[t]{2}{*}{ Reading time } & Test & 30 & 0.72 & 0.82 & \multirow[t]{2}{*}[0.11,0.79]{} & \multirow[t]{2}{*}{$2.65(58)$} & \multirow[t]{2}{*}{0.010} \\
\hline & Control & 30 & 0.27 & 0.44 & & & \\
\hline
\end{tabular}

a Difference was calculated as Test-Control. Cl, confidence interval

${ }^{b} \mathrm{df}$, degrees of freedom 
Some demographic factors were compared across the groups due to their potential influence on the parent's motivation to follow the recommended guidelines. The age of the parents may give us an indication of their level of education. The younger the parents, the more likely they are to be motivated to follow healthy guidelines for their children. The number and age of children in the family may indicate how busy the parents are, as more children could potentially limit the time parents could devote to each individual child, and children of different ages need different amounts of attention. No significant difference was, however, found between the two groups regarding these factors, and this would support the generalizability of the findings.

As to whether the primary prevention educational program impacted the families and their subsequent behavior: those that participated in the class which addressed screen-time and reading habits showed better understanding and compliance with the guidelines than those that had not. However, as to behavior modification, the only significant difference was found in the screen-time during the weekends. No such difference was found during weekdays. Part of this difference in screen-time between weekdays and weekends might be due to normal differences in family schedule between the weekdays and weekends. During weekdays, which are school/work days, parents might not impose restrictions on their children's use of screen devices to do homework or for entertainment/play during their short evening free times, or the parents might not have the time or the motivation to monitor their children's behavior after work; moreover, screen devices may even be used as a way to put the children out of the parents' way. During weekends, on the other hand, children have more free time and the parents have more time and energy to engage their children and organize healthier alternative activities, like going out with the family or letting the children play outside with their friends. Furthermore, when considering the average number of hours per day a child spent on screen devices aggregated for the whole week (weighted average), the difference was masked and no statistically significant difference was found.

When asked about the ideal screen-time for children, both groups reported a mean of less than $2 \mathrm{~h}$. When these means were compared to the recommended $2 \mathrm{~h} / \mathrm{day}$, only the mean of the test group was significantly different from the recommended threshold. This may indicate that the class the parents in the test group participated in had affected their knowledge regarding the importance of reducing their children's screen-time below the threshold. Yet, this was not enough to fully reduce screen-time to the recommended guidelines, thus showing that knowledge, alone, did not translate into an effective behavior modification.

Various preventive methods regarding excessive screen-time were used over the years. Some were obesity prevention programs and some targeted screen-time specifically. Educating the parents was found to be the most effective method in reducing children's screen-time in several studies (Bleakley et al., 2013; Harrison et al., 2006; Schmidt et al., 2012). Still, other methods should be implemented to reinforce knowledge and enhance outcome including: long-term programs with follow-up classes, the use of messaging services (SMS for example) to send educational messages (Shapiro et al., 2008), and the employment of active screen-time programs, like the use of video games that require physical activity (Lanningham-Foster et al., 2006). 
The other area addressed by this study was the reading habits of children. Although the children of the families in the test group read (or were being read to) more than the children in the control group, the mean reading time was still less than $1 \mathrm{~h} /$ day for both groups. Why was reading time so low? How reading has been adopted in Middle Eastern culture should be addressed. A recent report documented that the limited availability of books in houses in Jordan may be one cause for the limited reading time (Department of Statistics/Jordan and ICF, 2019). The parents' level of education and their interest in reading may also influence their children's love for reading (van Bergen et al., 2017), as modeling plays a key role in child development. Another factor might be that schools focus on reading for homework and not on extracurricular or leisure reading, as one Jordanian study showed that reduced reading time was linked to homework overload and the lack of motivation by teachers and parents (Batainah \& Al-Barakat, 2005).

In addition, the overuse of digital media can limit the time spent on reading. The data from this study showed that children from the test group spent 5 times more on their screen devices than on reading, compared to 16 times more for the control group. This is congruent with Banihani and Abu-Ashour (2015), who studied factors that affected reading habits of children in Jordan. In that study, they warned that digital media has captured much of the children's time, and that outside reading is not at the top of a child's preferred activities.

Parents, in both of our groups, were also under the impression that they should read to their children when they are older (about 3 years for our test group and about 4 years for our control group). Therefore, more comprehensive educational programs need to be developed to stress the importance of reading for the cognitive development of children, and to encourage parents to associate their children with books from infancy.

As shown in the findings, the calculation of a Pearson product-moment correlation from our data showed no significant correlation between screen-time and reading time for either group. This is similar to findings by Vandewater et al. (2006), but in contrast to several others who did find a relationship between screen-time and reading times (Khan et al., 2017; Koolstra \& van der Voort, 1996). This inability to find a correlation could have been due to the small sample size of the groups, or due to some factors that were not considered in this study.

\section{Limitations}

The information about the children was obtained from their parents and, thus, might not have reflected the actual behavior of those children. Direct child interview or behavior monitoring might have been more appropriate, but this could not be implemented in this study. Despite our best efforts, we were only able to encourage few families to participate in our programs, and thus obtained only 30 families for each group. This might have led to sampling error. In addition, although we measured three factors that we thought might affect our study variables, there could have been some other potentially effective confounding factors that were not considered. 


\section{Conclusion and recommendations}

The results from the current findings in Jordan are fairly congruent with studies elsewhere that have shown the increasing global trend of screen device overuse among children, but they also indicated some possible remedy. The use of pediatric primary prevention programs to educate families can contribute to improving parental knowledge of appropriate thresholds for children's screen-time and desirable reading habits. Short, simple programs raise awareness about the guidelines and produce some behavioral changes, but they are not sufficient to make the parents fully adopt the recommended guidelines.

Comprehensive long-term programs may be required to achieve the desired goals and/or other methods may need to be employed to provide and reinforce the necessary educational material or to motivate parents/children to adopt a healthier behavior. Further research into reading is recommended to explore the differences between weekday/ weekend reading, parent-child/child only reading, and paper/digital book reading.

The study of all aspects of a child's life-style behaviors (screen-time, reading habits, physical activity, eating habits, etc.) as a whole will give us an even better understanding of the effects these factors have on the child's health and future development, for to fully understand the mountain, it is not enough to examine only a single cave.

Acknowledgements

Not applicable.

Authors' contributions

All authors contributed equally to this work. All authors read and approved the final manuscript.

Funding

This research did not receive any grant from funding agencies in the public, commercial, or not-for-profit sectors.

Availability of data and materials

The datasets used and/or analyzed during the current study are available from the corresponding author on request.

\section{Declarations}

Ethical approval and consent to participate

This research was approved by the Institutional Review Boards of the Hashemite University and Prince Hamza Hospital where the research was conducted.

Informed consent

Informed consent was obtained from all individual participants included in the study.

Competing interests

The authors declare that they have no competing interests.

\section{Author details}

${ }^{1}$ Department of Basic Medical Sciences, Faculty of Medicine, The Hashemite University, Zarqa, Jordan. ${ }^{2}$ Business School, Hamdan Bin Mohammed Smart University, Dubai, United Arab Emirates. ${ }^{3}$ Department of Pediatrics, Faculty of Medicine, The Hashemite University, Zarqa, Jordan.

Received: 2 December 2019 Accepted: 20 October 2021

Published online: 28 October 2021

\footnotetext{
References

Academy and of Pediatrics Council on Communication and Media. (2013). Policy statement: Children, adolescents, and the media. Pediatrics, 132(5), 958-961. https://doi.org/10.1542/peds.2013-2656

Al-Dalaeen, A., \& Al-Domi, H. (2017). Factors associated with obesity among school children in Amman, Jordan. Malaysian Journal of Nutrition, 23, 211-218.

Al-Ghamdi, S. H. (2013). The association between watching television and obesity in children of school-age in Saudi Arabia. Journal of Family and Community Medicine, 20(2), 83-89. https://doi.org/10.4103/2230-8229.114767
} 
Al-Hazzaa, H. M., Abahussain, N. A., Al-Sobayel, H. I., Qahwaji, D. M., \& Musaiger, A. O. (2012). Lifestyle factors associated with overweight and obesity among Saudi adolescents. BMC Public Health, 12, 354-354. https://doi.org/10.1186/ 1471-2458-12-354

Anderson, S. E., Economos, C. D., \& Must, A. (2008). Active play and screen time in US children aged 4 to 11 years in relation to sociodemographic and weight status characteristics: A nationally representative cross-sectional analysis. BMC Public Health, 8, 366. https://doi.org/10.1186/1471-2458-8-366

Banihani, M. S., \& Abu-Ashour, K. M. (2015). The role of Jordanian schools in encouraging students' outside reading. Journal of Education and Social Policy, 2(1), 72-77.

Barr, R. (2010). Transfer of learning between 2D and 3D sources during infancy: Informing theory and practice. Developmental Review, 30(2), 128-154. https://doi.org/10.1016/j.dr.2010.03.001

Bataineh, R. F., \& Al-Barakat, A. A. (2005). The reading interests of Jordanian first-, second and third-grade pupils and the obstacles limiting these interests. Journal of Educational and Psychological Sciences. https://doi.org/10.12785/JEPS/060305

Beentjes, J. W. J., \& van der Voort, T. H. A. (1989). Television and young people's reading behaviour: A review of research. European Journal of Communication, 4(1), 51-77. https://doi.org/10.1177/0267323189004001004

Bener, A., Al-Mahdi, H. S., Ali, A. I., Al-Nufal, M., Vachhani, P. J., \& Tewfik, I. (2011). Obesity and low vision as a result of excessive internet use and television viewing. International Journal of Food Sciences and Nutrition, 62(1), 60-62. https://doi.org/10. 3109/09637486.2010.495711

Bleakley, A., Jordan, A. B., \& Hennessy, M. (2013). The relationship between parents' and children's television viewing. Pediatrics, 132(2), e364-371. https://doi.org/10.1542/peds.2012-3415

Brislin, R. W. (1970). Back-translation for cross-cultural research. Journal of Cross-Cultural Psychology, 1(3), 185-216. https://doi. org/10.1177/135910457000100301

Buscemi, J., Odoms-Young, A., Stolley, M. R., Schiffer, L., Blumstein, L., Clark, M. H., Berbaum, M. L., McCaffrey, J., Braunschweig, C., \& Fitzgibbon, M. (2019). Comparative effectiveness trial of an obesity prevention intervention in EFNEP and SNAP-ED: Primary outcomes. Nutrients. https://doi.org/10.3390/nu11051012

Canadian Paediatric Society Digital Health Task Force. (2017). Screen time and young children: Promoting health and development in a digital world. Paediatrics and Child Health, 22(8), 461-468. https://doi.org/10.1093/pch/pxx123

Cao, H., Qian, Q., Weng, T., Yuan, C., Sun, Y., Wang, H., \& Tao, F. (2011). Screen time, physical activity and mental health among urban adolescents in China. Preventive Medicine, 53(4-5), 316-320. https://doi.org/10.1016/j.ypmed.2011.09.002

Chacar, H., \& Salameh, P. (2011). Public schools adolescents' obesity and growth curves in Lebanon. Le Journal médical libanais. The Lebanese Medical Journal, 59, 80-88.

Fakhouri, T. H., Hughes, J. P., Brody, D. J., Kit, B. K., \& Ogden, C. L. (2013). Physical activity and screen-time viewing among elementary school-aged children in the United States from 2009 to 2010. JAMA Pediatrics, 167(3), 223-229. https://doi. org/10.1001/2013.jamapediatrics.122

Faught, E. L., Ekwaru, J. P., Gleddie, D., Storey, K. E., Asbridge, M., \& Veugelers, P. J. (2017). The combined impact of diet, physical activity, sleep and screen time on academic achievement: A prospective study of elementary school students in Nova Scotia, Canada. International Journal of Behavioral Nutrition and Physical Activity, 14(1), 29. https://doi.org/10.1186/ s12966-017-0476-0

Garmy, P., Clausson, E. K., Nyberg, P., \& Jakobsson, U. (2018). Insufficient sleep is associated with obesity and excessive screen time amongst ten-year-old children in Sweden. Journal of Pediatric Nursing, 39, e1-e5. https://doi.org/10.1016/j.pedn. 2017.11.009

Habib-Mourad, C., Ghandour, L. A., Moore, H. J., Nabhani-Zeidan, M., Adetayo, K., Hwalla, N., \& Summerbell, C. (2014). Promoting healthy eating and physical activity among school children: Findings from Health-E-PALS, the first pilot intervention from Lebanon. BMC Public Health, 14(1), 940. https://doi.org/10.1186/1471-2458-14-940

Hargrave, A. C., \& Senechal, M. (2000). A book reading intervention with preschool children who have limited vocabularies: The benefits of regular reading and dialogic reading. Early Childhood Research Quarterly, 15(1), 75. https://doi.org/10. 1016/S0885-2006(99)00038-1

Harrison, M., Burns, C. F., McGuinness, M., Heslin, J., \& Murphy, N. M. (2006). Influence of a health education intervention on physical activity and screen time in primary school children: 'Switch Off-Get Active.' Journal of Science and Medicine in Sport, 9(5), 388-394. https://doi.org/10.1016/j.jsams.2006.06.012

Hinkley, T., Salmon, J., Okely, A. D., Crawford, D., \& Hesketh, K. (2012). Preschoolers' physical activity, screen time, and compliance with recommendations. Medicine and Science in Sports and Exercise, 44(3), 458-465. https://doi.org/10.1249/MSS. Ob013e318233763b

Department of Statistics/Jordan, \& ICF (2019). Jordan population and family health survey 2017-18. Amman, Jordan, and Rockville, Maryland, USA: Department of Statistics/Jordan and ICF.

Kenney, E. L., \& Gortmaker, S. L. (2017). United States adolescents' television, computer, videogame, smartphone, and tablet use: Associations with sugary drinks, sleep, physical activity, and obesity. The Journal of Pediatrics, 182, 144-149. https:// doi.org/10.1016/j.jpeds.2016.11.015

Khan, A., Uddin, R., \& Burton, N. W. (2018). Insufficient physical activity in combination with high screen time is associated with adolescents' psychosocial difficulties. International Health, 10(4), 246-251. https://doi.org/10.1093/inthealth/ihy019

Khan, K. S., Purtell, K. M., Logan, J., Ansari, A., \& Justice, L. M. (2017). Association between television viewing and parent-child reading in the early home environment. Journal of Developmental and Behavioral Pediatrics, 38(7), 521-527. https://doi. org/10.1097/DBP.0000000000000465

Koolstra, C. M., \& van der Voort, T. H. A. (1996). Longitudinal effects of television on children's leisure-time reading: A test of three explanatory models. Human Communication Research, 23(1), 4-35. https://doi.org/10.1111/j.1468-2958.1996.tb003 $85 . x$

Lanningham-Foster, L., Jensen, T. B., Foster, R. C., Redmond, A. B., Walker, B. A., Heinz, D., et al. (2006). Energy expenditure of sedentary screen time compared with active screen time for children. Pediatrics, 118(6), e1831-1835. https://doi.org/10. 1542/peds.2006-1087

Lesnick, J., Goerge, R. M., Smithgall, C., \& Gwynne, J. (2010). Reading on grade level in third grade: How is it related to high school performance and college enrollment? Chapin Hall at the University of Chicago. 
Ling, R., \& Haddon, L. (2008). Children, youth and the mobile phone. In K. Drotner \& S. Livingston (Eds.), International handbook of children, media and culture (pp. 137-151). SAGE Publications.

Madigan, S., Browne, D., Racine, N., Mori, C., \& Tough, S. (2019). Association between screen time and children's performance on a developmental screening test. JAMA Pediatrics, 173(3), 244-250. https://doi.org/10.1001/jamapediatrics.2018.5056

Mitchell, E. A., Beasley, R., Bjorksten, B., Crane, J., Garcia-Marcos, L., \& Keil, U. (2013). The association between BMI, vigorous physical activity and television viewing and the risk of symptoms of asthma, rhinoconjunctivitis and eczema in children and adolescents: ISAAC Phase Three. Clinical and Experimental Allergy, 43(1), 73-84. https://doi.org/10.1111/cea.12024

Munzer, T. G., Miller, A. L., Weeks, H. M., Kaciroti, N., \& Radesky, J. (2019). Differences in parent-toddler interactions with electronic versus print books. Pediatrics, 143(4), e20182012. https://doi.org/10.1542/peds.2018-2012

Murray, A., \& Egan, S. M. (2014). Does reading to infants benefit their cognitive development at 9-months-old? An investigation using a large birth cohort survey. Child Lanquage Teaching and Therapy, 30(3), 303-315. https://doi.org/10.1177/ 0265659013513813

Nathanson, A. I., \& Beyens, I. (2018). The relation between use of mobile electronic devices and bedtime resistance, sleep duration, and daytime sleepiness among preschoolers. Behavioral Sleep Medicine, 16(2), 202-219. https://doi.org/10. 1080/15402002.2016.1188389

Parent, J., Sanders, W., \& Forehand, R. (2016). Youth screen time and behavioral health problems: The role of sleep duration and disturbances. Journal of Developmental and Behavioral Pediatrics, 37(4), 277-284. https://doi.org/10.1097/DBP.00000 00000000272

Paw, M. J. C. A., Singh, A. S., Brug, J., \& van Mechelen, W. (2008). Why did soft drink consumption decrease but screen time not? Mediating mechanisms in a school-based obesity prevention program. International Journal of Behavioral Nutrition and Physical Activity., 5(1), 41. https://doi.org/10.1186/1479-5868-5-41

Robinson, T. N., Matheson, D. M., Kraemer, H. C., Wilson, D. M., Obarzanek, E., Thompson, N. S., Alhassan, S., Spencer, T. R., Haydel, K. F., Fujimoto, M., Varady, A., \& Killen, J. D. (2010). A randomized controlled trial of culturally tailored dance and reducing screen time to prevent weight gain in low-income African American girls: Stanford GEMS. Archives of Pediatrics and Adolescent Medicine, 164(11), 995-1004. https://doi.org/10.1001/archpediatrics.2010.197

Schmidt, M. E., Haines, J., O'Brien, A., McDonald, J., Price, S., Sherry, B., \& Taveras, E. M. (2012). Systematic review of effective strategies for reducing screen time among young children. Obesity, 20(7), 1338-1354. https://doi.org/10.1038/oby.2011. 348

Shapiro, J. R., Bauer, S., Hamer, R. M., Kordy, H., Ward, D., \& Bulik, C. M. (2008). Use of text messaging for monitoring sugar-sweetened beverages, physical activity, and screen time in children: A pilot study. Journal of Nutrition Education and Behavior, 40(6), 385-391. https://doi.org/10.1016/j.jneb.2007.09.014

Sharif, I., \& Sargent, J. D. (2006). Association between television, movie, and video game exposure and school performance. Pediatrics, 118(4), e1061-1070. https://doi.org/10.1542/peds.2005-2854

Sherwood, N. E., Levy, R. L., Seburg, E. M., Crain, A. L., Langer, S. L., JaKa, M. M., Kunin-Batson, A., \& Jeffery, R. W. (2019). The healthy homes/healthy kids 5-10 obesity prevention trial: 12 and 24-month outcomes. Pediatric Obesity, 14(8), e12523. https://doi.org/10.1111/ijpo.12523

Stiglic, N., \&Viner, R. M. (2019). Effects of screentime on the health and well-being of children and adolescents: A systematic review of reviews. British Medical Journal Open, 9(1), e023191. https://doi.org/10.1136/bmjopen-2018-023191

Swing, E. L., Gentile, D. A., Anderson, C. A., \& Walsh, D. A. (2010). Television and video game exposure and the development of attention problems. Pediatrics, 126(2), 214-221. https://doi.org/10.1542/peds.2009-1508

Tayyem, R., Al-Hazzaa, H., Abumweis, S., Bawadi, H., Hammad, S., \& Musaiger, A. (2014). Dietary habits and physical activity level among Jordanian adolescents attending private versus public schools. Eastern Mediterranean Health Journal, 20, 411-418. https://doi.org/10.26719/2014.20.7.416

Twenge, J. M., Krizan, Z., \& Hisler, G. (2017). Decreases in self-reported sleep duration among U.S. adolescents 2009-2015 and association with new media screen time. Sleep Medicine, 39, 47-53. https://doi.org/10.1016/j.sleep.2017.08.013

van Bergen, E., van Zuijen, T., Bishop, D., \& de Jong, P. F. (2017). Why are home literacy environment and children's reading skills associated? What parental skills reveal. Reading Research Quarterly, 52(2), 147-160. https://doi.org/10.1002/rrq.160

Vandewater, E. A., Bickham, D. S., \& Lee, J. H. (2006). Time well spent? Relating television use to children's free-time activities. Pediatrics, 117(2), e181-191. https://doi.org/10.1542/peds.2005-0812

Wang, L., Lee, H., \& Ju, D. Y. (2019). Impact of digital content on young children's reading interest and concentration for books. Behaviour and Information Technology, 38(1), 1-8. https://doi.org/10.1080/0144929X.2018.1502807

Wigfield, A., Gladstone, J. R., \& Turci, L. (2016). Beyond cognition: Reading motivation and reading comprehension. Child Development Perspectives, 10(3), 190-195. https://doi.org/10.1111/cdep.12184

Wolf, C., Wolf, S., Weiss, M., \& Nino, G. (2018). Children's environmental health in the digital era: Understanding early screen exposure as a preventable risk factor for obesity and sleep disorders. Children (basel). https://doi.org/10.3390/children50 20031

Wu, L., Sun, S., He, Y., \& Jiang, B. (2016). The effect of interventions targeting screen time reduction: A systematic review and meta-analysis. Medicine, 95(27), e4029. https://doi.org/10.1097/MD.0000000000004029

Yuill, N., \& Martin, A. F. (2016). Curling up with a good e-book: Mother-child shared story reading on screen or paper affects embodied interaction and warmth. Frontiers in Psychology, 7, 1951-1951. https://doi.org/10.3389/fpsyg.2016.01951

Zhu, Z., Ma, S., Bai, Y., Tang, Y., Zhuang, J., Liu, Y., Chen, P., \& Cao, Z.-B. (2018). Associations of physical activity and screen time with obesity in Chinese children and adolescents: 2854 board \#137 June 1200 PM - 330 PM. Medicine and Science in Sports and Exercise, 50(5S), 702. https://doi.org/10.1249/01.mss.0000538314.30417.9f

\section{Publisher's Note}

Springer Nature remains neutral with regard to jurisdictional claims in published maps and institutional affiliations. 